due to anthropogenic climate warming and changing precipitation patterns. However, how quickly or slowly an individual glacier responds to climate changes is dependent upon a variety of properties, including glacier size, historical mass-balance patterns, prevailing weather patterns and other factors. Shugar et al. find that the retreat of Kaskawulsh Glacier is highly likely to be caused by recent climate change.

Ultimately, changing drainage patterns have impacts beyond the immediate area. If a river changes course so drastically that the drainage basin no longer reaches its original outlet, this change might eventually impact human and biological communities that have grown around the river's original outlet. The river's new outlet would eventually need to adapt to enhanced flow and material flux. Although in this case the outflow through the
Yukon might not be tremendously affected, an increase in water and sediment discharge to the Alsek River might potentially change landscape evolution far downstream the glacier. As the world warms and more glaciers melt, populations dependent upon glacial meltwater should pay special attention to these processes. Additionally, the impacts should catch the attention of not only those who study rivers and climate change, but also of anyone interested in water, sediment and nutrient supplies.

Shugar and co-authors ${ }^{1}$ have captured a unique impact of climate change: river piracy, due to retreating and melting glaciers. It may pay off for ecologists, policymakers and any industries operating near glaciated or high-latitude coastal regions to keep an eye out for nearby drainage reorganizations as the ice retreats.
Rachel M. Headley is in the Geosciences

Department, University of Wisconsin-Parkside, 900 Wood Road, Kenosha, Wisconsin 53141, USA. e-mail: headley@uwp.edu

References

1. Shugar, D. H. et al. Nat. Geosci. 10, 370-375 (2017).

2. Davis, W. M. Science 13, 108-109 (1889).

3. Willett, S. D., McCoy, S. W., Perron, J. T., Goren, L. \& Chen, C. Y. Science 343, 1117 (2014)

4. Bishop, P. Prog. Phys. Geog. 19, 449-473 (1995).

5. Carson, E. C., Rawling, J. E. III, Attig, J. W. \& Bates, B. R. in Abstracts with Programs - 125th Annual Meeting and Expo Vol. 45, 192 (Geological Society of America, 2013)

6. Foy, N., Copland, L., Zdanowicz, C., Demuth, M. \& Hopkinson, C. J. Glaciol. 57, 515-525 (2011).

Bostock, H. S. Geol. Surv. Canada. http://dx.doi.org 10.4095/104706 (1969)

8. Clague, J. J. et al. Quat. Res. 66, 342-355 (2006).

9. Roe, G. H., Baker, M. B. \& Herla, F. Nat. Geosci. 10, 95-99 (2017).

Published online: 17 April 2017

Corrected online: 19 April 2017

\title{
DEFORESTATION
}

\section{Accelerating riverbank erosion}

Trees are important stabilizing agents in many landscapes. Root systems can bind together soil and regolith on steep hillslopes. They can also strengthen riverbanks, and thereby help control the evolution of riverine morphology. When roots bind the riverbank, it tends to collapse into the river intermittently, in larger blocks, rather than more continuously in smaller pieces. These large blocks disrupt the flow of the river and protect the riverbank against further erosion.

However, tropical forests are widely threatened by deforestation; for example, to make way for the sprawling palm-oil plantations of Indonesia. The long-term impact of deforestation on the morphology of rivers in affected areas remains poorly understood.

Using a series of satellite images of the Kinabatangan River in Sabah, Malaysia and its meandering route through its floodplain, Horton and co-authors trace the history of the interaction between deforestation and bank erosion (Geology http://doi.org/ b5bm; 2017). As for many tropical rivers in settings from the Amazon to Kenya, the natural vegetation has been completely removed over the past decades along stretches of the Kinabatangan River. The satellite images show that where forests have been stripped away for agriculture, the erosion of meanders is at least $23 \%$ faster between 1984 and 2014 than for natural systems.

Approximations of flow velocities suggest that riverbanks without natural

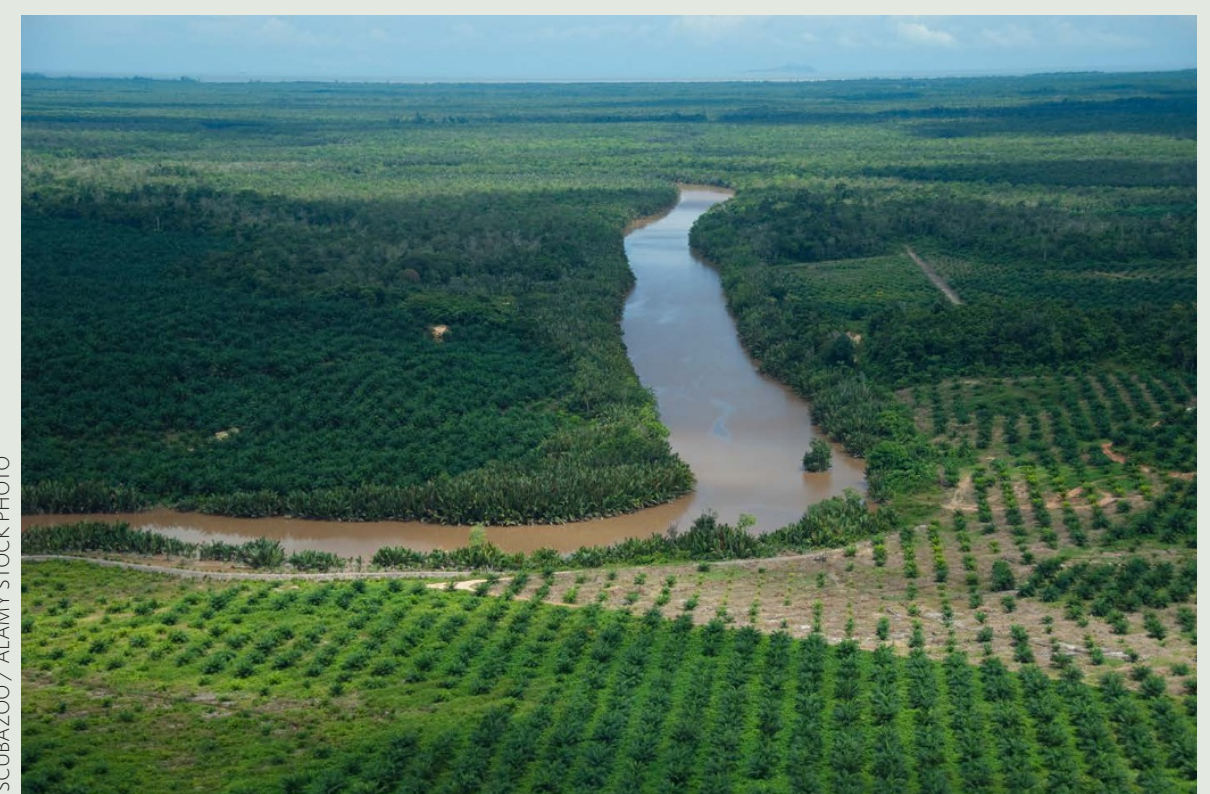

forest retreat at a greater rate for the same average water flow rate. Trees play multiple roles in riverbank ecosystems: as well as binding riverbanks with root systems, they also reduce the infiltration of rainwater into the soil through evapotranspiration. Without trees, the pore pressure in the bank substrate could increase and lead to a loss of cohesion and potential collapse into the eroding river. These effects are even dominant in these large rivers where the height of the riverbank exceeds the depth to which the roots penetrate.
Deforestation interrupts the intricate feedbacks and connections between biology, landscape and water. The impacts of deforestation on river networks are yet another aspect of how anthropogenic changes are imprinted onto modern geomorphic processes, both locally and downstream, as sediment fluxes are boosted by increases in erosion. Conservation efforts to protect natural forests may thus also have the unintended effect of stabilizing rivers.

ROBERT EMBERSON 